\title{
"humanidades
}

Revista Humanidades

ISSN: 2215-3934

humanidades@ucr.ac.cr

Universidad de Costa Rica

Costa Rica

\section{El sentido pedagógico de las artes en las carreras de Licenciatura en Artes y Pedagogía en Artes en Chile}

Schenffeldt Ulloa, Mg(c). Ninoska; García-Huidobro Munita, Dra. Rosario

El sentido pedagógico de las artes en las carreras de Licenciatura en Artes y Pedagogía en Artes en Chile

Revista Humanidades, vol. 11, núm. 2, 2021

Universidad de Costa Rica, Costa Rica

Disponible en: https://www.redalyc.org/articulo.oa?id=498066660006

DOI: https://doi.org/10.15517/h.v11i2.47312

\section{(c) (1) $(\Theta)$}

Esta obra está bajo una Licencia Creative Commons Atribución-NoComercial-SinDerivar 3.0 Internacional. 
Desde las ciencias sociales, filosofía y educación

\title{
El sentido pedagógico de las artes en las carreras de Licenciatura en Artes y Pedagogía en Artes en Chile
}

\author{
The Pedagogical Sense of the Arts in the Careers of Bachelor of Arts and Pedagogy in Arts in Chile \\ $M g(c)$. Ninoska Schenffeldt Ulloa \\ DOI: https://doi.org/10.15517/h.v11i2.47312 \\ Universidad de los Lagos, Chile \\ ninoska.schenffeldt@ulagos.cl \\ Redalyc: https://www.redalyc.org/articulo.oa? \\ $\mathrm{id}=498066660006$
}

iD https://orcid.org/0000-0002-1401-9437

Dra. Rosario García-Huidobro Munita

Universidad de los Lagos, Chile

rosario.garcia-huidobro@ulagos.cl

iD https://orcid.org/0000-0002-3454-4511

Recepción: 01 Febrero 2021

Aprobación: 03 Junio 2021

\section{Resumen:}

Este artículo se centra en un estudio que buscó comprender los vínculos entre las prácticas artísticas y pedagógicas de artistas y docentes artistas en Chile, donde dichos cruces son potenciales para generar nuevas propuestas de producción artística que cuestionan las formas tradicionales de producción artística. Se trabajó con las carreras de Licenciatura en Artes y Pedagogía en Artes y se analizó en qué medida la academia muestra los cruces entre lo artístico y lo pedagógico al estudiantado de Artes en Chile. El estudio puso énfasis en identificar cómo se enseña lo artístico como proceso de relación, elemento que llamamos lo pedagógico en el arte. Se realizaron entrevistas semiestructuradas a las principales jefaturas de carreras artísticas del país. Tras el análisis se identificó la categoría sobre las características del sentido pedagógico, lo que alude a la pregunta por el cómo se promueve. En segundo lugar, se identificó la categoría agentes de cambio, la cual responde a la pregunta por quiénes promueven dicho sentido pedagógico en las carreras, y se observó que principalmente era promovido por el estudiantado y el profesorado. Estos(as) agentes son quienes constantemente están generando acciones de transformación desde lo artístico hacia las comunidades y dotando de sentido pedagógico a las prácticas artísticas.

Palabras ClaVe: formación de agentes culturales, formación de docentes, artes, cambio social.

\section{ABstract:}

This article focuses on a study carried out in Chile, which seeks to understand how the Bachelor of Arts and Pedagogy in Arts careers show the intersections between the artistic and the pedagogical to the student body. Emphasis was placed on identifying how the artistic is taught as a process of relationship, an element that we call the pedagogical in art. For this, semi-structured interviews were carried out with the main artistic careers headquarters in the country. After the analysis, three categories could be established, however in this article two are addressed. First, the characteristics of the pedagogical sense were identified, which alludes to the question of how it is promoted. The second element that was observed in the analysis was the question of who promotes this pedagogical sense in the careers and it was observed that it was mainly promoted by the students and teachers, whom we call agents of change. These agents are the ones who are constantly generating transformation actions from the artistic to the communities and providing a pedagogical sense to artistic practices.

KEYWORDS: training of cultural agents, training of teachers, arts, visual arts, social change.

\section{INTRODUCCIÓN}

En el presente artículo se muestran algunos de los resultados de la investigación n. ${ }^{\circ} 11180057$, titulada Nuevos vínculos y desafíos entre lo artístico y lo pedagógico. Abriendo campos hacia una re-conceptualización del arte y el 
rol del/la artista en la sociedad actual, realizada en Chile entre 2018 y 2020, a través de los Fondos Nacionales de Ciencia y Tecnología ${ }^{1}$.

El principal objetivo de este estudio fue conocer la vinculación entre la práctica artística y la práctica pedagógica en las personas que son artistas visuales y artistas-docentes. Esto se hizo con el fin de identificar, en estos cruces, el potencial para generar nuevas propuestas en la producción artística y la educación artística en Chile.

Dado que el estudio se desarrolló en diversas etapas y atendiendo a distintos objetivos específicos, el presente artículo se centra en uno de los cuatro objetivos específicos de este proyecto: explorar las formas en las que se fomentan los vínculos entre la práctica artística y docente en las carreras de Licenciatura en Artes y Pedagogía en Educación Artística en Chile; en estos espacios universitarios se definen modos de ser artistas en el mundo, formas de enseñar las artes y se les muestra a los estudiantes sus posibles espacios de acción dentro de la realidad social.Este proyecto tomó como base el giro educativo en las artes, ya que este ha planteado nuevos desafíos (Rogoff, 2011). En este sentido, las prácticas artísticas contemporáneas comenzaron a cuestionar las formas tradicionales de enseñanza, de lo que emergió la siguiente interrogante: ¿cómo generar nuevos vínculos entre las artes, las instituciones y las problemáticas sociales como respuesta a la necesidad de generar nuevas relaciones y conocimientos desde las artes? De esta manera, este estudio surge del interés por encontrar elementos pedagógicos en las prácticas de artistas y colectivos de artistas en Chile y cómo, a su vez, el quehacer docente que realizan artistas en espacios de enseñanza (formal o informal) abriría posibilidades de re-significación de las prácticas artísticas.

Se reconocen los profundos cambios que han ido transcurriendo en las áreas artísticas como resultado del giro educativo; los desafíos que enfrentan artistas promueven transformaciones sociales y culturales que, en Chile, se han manifestado desde diversos proyectos. Por ejemplo, el programa nacional Residencias de Arte Colaborativo, impulsado por el Ministerio de las Culturas, las Artes y el Patrimonio, es uno de los programas que promueven la participación ciudadana, ya que al situar a los artistas o colectivos artísticos en un territorio o comunidad específica durante tres o seis meses, permiten que estos se vinculen con el contexto: uniendo el espacio de trabajo artístico con los lenguajes territoriales propios de la zona. De esta manera, el ejercicio artístico colaborativo que se desarrolla en este programa de residencias propicia la cultura, los diálogos comunitarios y la acción pedagógica a través de prácticas artísticas que generan sentido a la comunidad, sin convertirse en un espacio formativo sino de transmisión o desarrollo de prácticas artísticas en los habitantes de los territorios. En otras palabras, más que una transferencia de conocimientos es la entrega de una experiencia artística significativa, donde se introduce el arte como medio y aspecto novedoso, capaz de erguir nuevos significados o re-significar los ya existentes.

Siguiendo con lo anterior, estos cambios surgen de la necesidad de construir la sociedad como un proyecto colectivo. A partir de esto, se conforman espacios de resistencia ante la productividad hegemónica y se insertan nuevas subjetividades, o bien se resignifican las ya instauradas. De esta manera, surgen grupos que desarrollan prácticas artísticas alineadas con movimientos sociales y nuevas propuestas de reivindicación social, además, estos grupos se vinculan con ciertas prácticas activistas y pedagógicas (MesiasLema, 2018). Estas propuestas expanden el arte como proyecto educativo que va más allá del aula y las barreras academicistas a favor de un interés común y propositivo vinculado con el aspecto social.

En las artes, el sentido pedagógico es la conceptualización resultante de los cambios y las expansiones de los lenguajes y prácticas que interpelan al campo artístico y que buscan dotarlo de un rol más social y político. De este modo, el objetivo es que se aleje de la mera producción estética, ya que la finalidad de las artes ligadas al componente social no es la culminación de una obra, sino la promoción de experiencias significativas que permitan dinamizar procesos personales o comunitarios. A esto último se le llamará rol político de las artes, lo cual es, finalmente, la interpelación del arte como praxis emancipadora (Guerra, 2017).

El llamado político de las artes surge al interpretar las lógicas del arte contemporáneo y la forma en la que estas van dialogando con las relaciones sociales (Bourriaud, 2017) con énfasis en lo educativo, ámbito 
en el que la mediación emerge como práctica crítica (Mörsch, 2015). Desde esta perspectiva, el quehacer artístico traspasa el producto estético y se sitúa en la experiencia estética como posibilidad que abre las oportunidades de transformación, donde lo artístico se descubre desde lo intersubjetivo como herramienta de transformación social (Moreno, 2013,2016) y no como un fin en sí mismo.

Desde estos nuevos discursos y prácticas del campo artístico, la escuela, entendida como espacio formal, posibilitadora de enseñanza y de formación, también se modifica hacia nuevos modelos pedagógicos y se desmarca del autoritarismo y el paternalismo que limitan el proceso solo a la entrega de conocimientos y contenidos para formar una persona funcional. De este modo, la persona docente también es una figura errante (Rodrigo y Collados, 2014), involucrada en este proceso de enseñanza y aprendizaje que le da voz a las experiencias del estudiantado, aprende de ello y que posibilita un encuentro y una mediación de subjetividades para que se genere algo nuevo. Así pues, aquí es donde lo artístico emerge como una oportunidad para el encuentro colectivo; el producto artístico es, en sí mismo, las conexiones y las mediaciones de experiencias parciales de las personas que confluyeron en reflexiones, devenires relacionales y que permitieron dicha creación.

Dado lo anterior, se vuelve imprescindible indagar la forma en la que se está socializando el sentido pedagógico en Chile. Para ello, es relevante conocer cómo se muestra el sentido pedagógico de las artes en las universidades donde se imparten carreras como Licenciatura en Artes y Pedagogía en Educación Artística, ya que son instituciones de enseñanza formal cuyo enfoque principal es el eje educativo, la enseñanza de las artes y el pensamiento crítico. Por lo tanto, es necesario comprender el sentido que dan a lo pedagógico en tanto práctica educativa.

Para este estudio fue relevante conocer en qué medida las nuevas demandas sociales y políticas, que emergen del campo artístico, permean los ámbitos academicistas de las artes. Para indagar dicha temática, se realizaron entrevistas semiestructuradas a las principales autoridades académicas de diez universidades chilenas. En dichos centros educativos se imparten las carreras de Licenciatura en Artes y Pedagogía en Educación Artística. Ahora bien, a partir del análisis de sus relatos, se distinguieron dos principales elementos del sentido pedagógico encarnado en la institucionalidad académica y formadora de las artes.

El siguiente apartado se enfoca en la noción de sentido pedagógico, así como en sus principales conexiones con el quehacer artístico, pues estos conceptos guiaron el marco contextual del proyecto. Posteriormente, se explica tanto la metodología como el método utilizado en la investigación. Finalmente, se explican las dos categorías emergentes del análisis, las cuales se centran en las explicaciones sobre quiénes son las personas de las carreras de Licenciatura en Artes y Pedagogía en Artes en Chile que promueven sentidos pedagógicos vinculados con las artes y cómo logran fomentar esto.

\section{Marco teórico: el Sentido de lo Pedagógico en las artes}

En el presente apartado se explica cómo se han abordado los vínculos entre las artes y la educación, asimismo, se aludirá al sentido pedagógico (concepto clave que se indaga en este estudio) y a aquello que orientó los encuentros con las jefaturas de carreras en Chile.

En el último decenio se ha instalado con fuerza, en las áreas de las artes, un fenómeno que Rogoff (2011) explicó como el giro educativo. Este movimiento ha visibilizado una diversa cantidad de prácticas artísticas, expositivas, curatoriales, seminarios y congresos. Dichas prácticas han situado a lo educativo como un tema y un motor de creación artística. De esta manera, lo educativo ha sido explorado y presentado desde diferentes matices en las prácticas artísticas y de curaduría. Por ejemplo, en algunas prácticas artísticas y expositivas se ha indagado en la forma en la que el acto de pensar, enseñar y compartir se transforma en gesto y producción artística. Este es el caso del trabajo y el legado que entregó Joseph Beuys con su modelo de pedagogía como arte (Cercós i Raichs, 2017). Por consiguiente, se recogen aquí los trabajos de otros autores, por ejemplo, la artista cubana Tania Bruguera con su proyecto artístico Cátedra Arte de Conducta; el colectivo Nubol en 
España y sus etnografías artísticas con las muestras expositivas Ni Arte Ni Educación exhibidas en el Centro Matadero de Madrid en 2017; la muestra UnTeaching, promovida por la artista y curadora Mary Lempress en Nueva York. (García-Huidobro, Viveros-Reyes y Bahamonde-Courbis, 2020). En todas estas propuestas el acto de aprender y enseñar era central y se situaba como experiencia y dispositivo artístico. Otros caminos han explorado a lo educativo en las artes de una forma que no es explícita, ya que en estas experiencias lo educativo no es comprendido como la entrega de información o herramientas, sino más bien como una experiencia que es "capaz de provocar efectos transformadores en la sociedad. La educación también es política cultural, así como los maestros son también trabajadores culturales" (Rodrigo y Collado, 2014, p. 63). Ante estas ideas, se alude a artistas y colectivos de artes que han abordado lo artístico como una herramienta posibilitadora de experiencias sociales, culturales y políticas. Lo artístico, entonces, promueve otras formas de entender las relaciones sociales y, por ende, la oportunidad de descubrir nuevas significaciones y subjetividades.

Las personas, ya sea las que se dedicaran al arte, o bien a las labores académicas, desde fines del siglo XXI, tomaron las críticas posmodernas y comenzaron a encarar nuevos desafíos que no podían ignorar desde las artes y que se fueron plasmando en nuevas manifestaciones artísticas. De esta forma, los tipos de prácticas creativas que se enseñaban y desarrollaban en las escuelas de artes, las academias de artes y las universidades comenzaron a responder críticamente a aspectos sociales, políticos y culturales que cuestionaban el prototipo de artista genio(a), puesto que el artista contemporáneo debía ser "teórico, performer, productor, instalador, escritor, animador, y chamán” (Sullivan, 2010, p. 4). A estas características se pueden sumar, sin duda, otras más, por ejemplo, la de persona gestora, docente, mediadora, etnógrafa, las cuales dan cuenta de los múltiples escenarios y contextos en donde las artes pueden estar y reinventarse.

En este sentido, las prácticas artísticas y culturales comenzaron a ser comprendidas como espacios críticos de resistencia y escenarios creativos de investigación (Sullivan, 2010), los cuales empezaron a fomentar, desde nuevas perspectivas, otras formas de pensar y comprender las vidas de los seres humanos, puesto que se aferraban a elementos relacionales, colaborativos y comunitarios.

Estas ideas se han alimentado del rol social de las artes y, a su vez, han orientado el desarrollo de sus prácticas hacia espacios críticos de creación y producción que se exponen desde metodologías más relacionales y colaborativas. Entre ellas, las prácticas artísticas comunitarias que se comenzaron a fomentar desde los años setenta en Europa, las cuales mostraron toda una forma particular de hacer arte, donde la persona artista o colectivos se desprenden de la idea de que el artista o la artista produce su obra aislado(a) en su taller y, contrario a esto, se involucra en un hacer social, donde se trabajaban proyectos artísticos con comunidades locales. Además, desde esta perspectiva, el foco no está en los resultados, sino más bien en los procesos creativos experimentados a través de las artes y que permiten abordar problemas sociales.

Otro tipo de artes vinculadas con lo pedagógico son las prácticas activistas. Esta fue una de las estrategias que siguieron algunos grupos para desmarcarse de la institucionalidad del arte y buscar:

(...) modos de producción de formas estéticas y de relacionalidad que anteponen la acción social a la tradicional exigencia de autonomía del arte que es consustancial al pensamiento de la modernidad (...) El activismo artístico niega de facto esa separación, no exclusivamente en el plano teórico e ideológico, sino en la práctica (Expósito et al., 2012, p. 43).

Si bien el arte activista o artivista (Delgado, 2013) se desarrolló desde la Segunda Guerra Mundial en Europa, en Latinoamérica se conformó a partir de las dictaduras militares, en las que diversos artistas y colectivos buscaron visibilizar la situación social y política. Las prácticas artísticas activistas son muestras de arte comprometidas socialmente, por lo que los elementos pedagógicos expuestos en estas prácticas se relacionan con los actos de resistencias, cuyo objetivo es generar otros modos de subjetividad, lo que las constituye como espacios de emancipación de las personas.

Asimismo, otro tipo de práctica artística que encarna elementos pedagógicos es la mediación artística, la cual se relaciona con intervenciones sociales en las que las artes se ponen a disposición de una comunidad o grupo, con el fin de tratar temas específicos o problemas, pues se ve, en las formas artísticas, un medio o una 
metodología para la comprensión social colaborativa que genera agenciamientos y subjetividades (Moreno, 2016).

Se han podido trazar diversas líneas, en las cuales estas formas artísticas: comunitarias, activistas, sociales y colaborativas, han buscado intervenir los espacios sociales no únicamente en cuanto acción artística, sino también a través de la promoción de experiencias artísticas como una herramienta de mediación que genera nuevas ciudadanías e intersubjetividades. Estos procesos han situado a la persona artista como una figura que:

Adopta y se encamina hacia un interés por lo educativo, donde el objetivo es impulsar y fomentar a través de las artes, una acción y mecanismo de emancipación, que permita generar una transformación social hacia una comunidad. Es por eso que aproximarse a esta mirada dentro de esta esfera me parece importante abordarla desde una dimensión pedagógica, porque implica prestar atención a los aprendizajes colectivos y dinámicas de participación mediante la práctica artística (Zúñiga, 2019, p. 75).

Dado lo anterior, las prácticas artísticas y culturales que sitúan el foco en lo pedagógico plantean la idea de una educación expandida, ya que los procesos participativos abordados desde estas experiencias son siempre posibilitadores de encuentros sociales donde algo nuevo emerge. Esta última idea parece crucial cuando se analiza lo pedagógico en las artes, puesto que aluden al acontecimiento. Deleuze (1990) plantea la idea de acontecimiento como un devenir, una acción inmanente. Por otro lado, para Badiou (2002) el acontecimiento se relaciona con las rupturas que ocurren en los propios devenires. Guerra (2017) analiza las propuestas de ambos pensadores para plantear que un acontecimiento en las artes siempre permanecerá y resistirá como una posibilidad de algo. Por ende, se entiende que lo pedagógico será una característica de ese acontecimiento artístico, es decir, el que permitirá abrir algo nuevo, tanto en la estética o forma material como en su significado o afectación en las personas que participan de dicho proceso creativo.

Sobre ello, Miranda (2014) ha expresado que "la producción de experiencias, la generación de espacios de relación, la promoción de diversas formas de participación creativa, son nuevas maneras que no siempre remiten al objeto material visible, aquel que parece articular la tradición pedagógica” (p. 166). Desde estas ideas, se concibe a lo pedagógico en las artes como la posibilidad de generar una experiencia otra, un devenir o un acontecimiento.

Se entiende, entonces, que lo pedagógico será una dimensión inherente a todas las fases de la vida humana como un elemento que forma parte de la vida cotidiana (Luke, 1999) porque alude a las relaciones sociales que se van conformando con la realidad. Según Rodrigo (2010), hablar del sentido de lo pedagógico es un factor que "ha traspasado la cuestión de la escuela o el docente y se ha constituido como eje clave a la hora de pensar las relaciones entre democracia, cultura y sociedad" (p. 1). Por ello, se pensará en lo pedagógico como lo que Hernández (2011) ha llamado encuentro de subjetividades y de saberes compartidos; también como un proceso en el que se van construyendo diversas experiencias de ser, por lo tanto, lo pedagógico es transformativo y garante de nuevos saberes.

Ahora bien, en el contexto universitario, tanto estudiantes como profesores de artes están inmersos diariamente en una relación dialógica que cruza el hacer artístico y pedagógico. Kester (2011) llama arte dialógico a la posibilidad de generar otras formas de relación entre las personas que son partícipes de las prácticas artísticas. Algo similar a lo que Bourriaud (2017) ha planteado como la estética relacional y que apunta a las nuevas formas de hacer y entender a las artes contemporáneas, donde el encuentro relacional es central en el acontecimiento artístico. De hecho, este autor plantea que "si observamos las prácticas artísticas contemporáneas, más que 'formas', deberíamos hablar de 'formaciones', lo opuesto a un objeto cerrado en sí mismo por un estilo o una firma. El arte actual muestra que sólo hay forma en el encuentro" (Bourriaud, 2017, p. 22).

A partir de lo anterior, surge la siguiente inquietud: ¿en qué medida los procesos formativos del estudiantado de Artes Visuales y Pedagogía en Artes Visuales muestran que las artes son procesos abiertos, dinámicos, relacionales y formas de encuentro entre sujetos? Para responder esta pregunta es fundamental conocer las relaciones entre sujetos durante el proceso formativo de futuros artistas, así como las 
características que posee el vínculo artistas-docentes; de esta forma, se podría comprender cuál es el sentido que se le está dando a la experiencia artística dentro de las formaciones universitarias. Entonces, desde estas nuevas posibilidades y relaciones se puede ir "más allá de los límites impuestos por quienes consideran qué es el arte” (Hernández, 2009, p. 309). Más bien, lo que importa observar es la capacidad intencional del arte (Fontdevila, 2018) en los espacios formativos y de esta manera mostrar la capacidad de las artes como herramientas que afectan a las personas, disrumpen, abren a lo nuevo, a la diferencia y a las nuevas formas de entender(nos) en nuestra cotidianidad. A todo esto se le llama lo pedagógico y, finalmente, se resume como modos de experimentar las artes desde lo relacional, desde el encuentro y, además, se concibe como aquello que otorga a todas las personas participantes un saber nuevo que es propio y compartido.

\section{Metodología}

Para el desarrollo de este estudio se realizó un proceso cualitativo de recabación de información, el cual constó de tres fases y agrupó a diversas figuras que conformaron la muestra. Comprender como se fomentan los vínculos entre las artes y lo pedagógico llevó a analizar el trabajo y el relato de personas artistas y artistasdocentes, pero también los relatos de quienes forman a las futuras personas artistas y pedagogas en artes, ya que es, en esos espacios formativos, donde se siembra el sentido pedagógico de las prácticas artísticas.

Respecto de las fases, en la primera etapa de esta investigación se realizaron siete casos de estudio de artistasdocentes para analizar el desarrollo de sus proyectos artístico-pedagógicos. Posteriormente, en la segunda etapa, se llevaron a cabo ocho talleres artísticos de discusión (TAD) (García-Huidobro y Schenffeldt, en prensa) en formato presencial y virtual con grupos de artistas, artistas-docentes, mediadores(as) y estudiantes. El método de los TAD se desarrolló tomando elementos de la investigación basada en las artes, ya que es una metodología que emplea herramientas artísticas (visuales, literarias, performativas) para promover y desvelar información que no es posible obtener por otras vías de conocimiento (Barone y Eisner, 2006; Hernández, 2008). En la tercera etapa del estudio, se efectuaron quince entrevistas semiestructuradas a artistas. Por último (el foco de este escrito), se realizaron diez entrevistas semiestructuradas de manera online a las autoridades académicas de las carreras de Pedagogía en Artes y Licenciatura en Artes de las principales universidades de Chile.

Dado que el cuarto objetivo específico de este proyecto se enfocó en explorar cómo se fomentan los vínculos entre la práctica artística y docente en las carreras de Licenciatura en Artes y Pedagogía en Educación Artística, las entrevistas a las autoridades académicas de estas carreras fueron clave para comprender cuáles son las formas en las que se muestran las artes a las personas que serán futuras artistas y docentes de artes.

El diseño de participación de la muestra, que consta de un total de diez entrevistas, fue no probabilística y por conveniencia. Dicha muestra se divide de la siguiente forma: cinco entrevistas a las autoridades académicas de las carreras de Licenciatura en Artes y cinco a las autoridades académicas de Pedagogía en Artes en Chile.

A cada persona entrevistada se le entregó un consentimiento informado para grabar los relatos. La entrevista estaba constituida por seis preguntas:

1) ¿Cuál es el sentido pedagógico que se intenta promover en el aprendizaje artístico del estudiantado?

2) ¿Cómo la carrera enseña/muestra/promueve (o no) el vínculo entre lo artístico y lo pedagógico durante la carrera?

3) ¿Cómo piensas que lo hace, a través de qué elementos puedes identificarlo (profesores, malla, trabajos)

4) ¿Esto es algo que se pregunten como carrera o equipo académico?, ¿les interesa o preocupa?, ¿por qué?

5) ¿Cómo piensas que en la carrera se debería promover, en los futuros(as) artistas/ futuros(as) docentes de artes, el vínculo entre la práctica artística y el sentido pedagógico? 
6) ¿Cómo el hacer y pensar artístico que aprende el estudiantado en esta carrera es un aporte para la educación, las artes y las transformaciones sociales? y ¿cómo has visto que las personas exalumnas de esta carrera desarrollan este vínculo entre lo artístico y lo pedagógico?

La forma de abordar las preguntas por las personas entrevistadas fue desde un plano personal con base en sus apreciaciones y en sus experiencias. Además, la forma de abordar las preguntas fue desde un rol de autoridad académica, el cual cada persona ejerce en sus determinadas casas de estudio, lo que ofreció un amplio espectro de sus subjetividades.

Finalmente, las diez entrevistas fueron analizadas en el software Atlas.ti y tuvieron dos procesos de codificación. El primero fue una codificación con conceptos predefinidos que orientaron el proceso y el segundo fue un reordenamiento de las codificaciones, para comenzar a entrever la emergencia de unas categorías que daban sentido a sus relatos y esta búsqueda por lo pedagógico (ver Tabla 1). El análisis permitió observar tres elementos relevantes sobre el sentido pedagógico fomentado en las carreras entrevistadas. En primer lugar, se identificaron las características del sentido pedagógico y se alude a la pregunta ¿cómo se promueve? El segundo elemento relevante que se observó en el análisis fue con respecto a la pregunta ¿quiénes promueven dicho sentido pedagógico en las carreras? Se observó que, principalmente, era promovido por el estudiantado y el profesorado, a quienes se les llama agentes de cambio. En tercer y último lugar, se observaron diversas dificultades para promover el sentido pedagógico, las cuales incluían impedimentos institucionales, tales como los criterios establecidos por la Comisión Nacional de Acreditación y los propios aspectos curriculares de las carreras. Estos se relataron como aspectos que dificultaban la incorporación de elementos pedagógicos/transformativos en dichas carreras. De esta manera, en el siguiente apartado se muestran los principales resultados de esta fase investigativa, así como la articulación teórica que se realizó con los relatos y las reflexiones del profesorado de artes en Chile.

\section{Resultados}

\subsection{Manifestaciones del sentido pedagógico en las carreras de Artes y Pedagogía en Artes}

Al realizar las entrevistas correspondientes, se exploró en cómo las instituciones de educación superior en Chile fomentan los vínculos entre la práctica artística y docente en las carreras de Licenciatura en Artes y Pedagogía en Artes, evaluando sus cruces y diferencias. Se enfatizó en la idea de cómo la academia promueve el sentido pedagógico en su estudiantado, pero no comprendido como la acción de entregarles conocimientos, sino más bien como un interés en indagar en qué medida el currículum, la malla curricular y su profesorado les muestra a las personas discentes la experiencia artística como un encuentro de subjetividades y relaciones (Hernández, 2011), lo que aquí se llama el sentido de lo pedagógico.

En el análisis se evidencian dos grandes categorías (ver Tabla 1), las cuales permitieron identificar y reflexionar sobre el sentido pedagógico en las carreras de Licenciatura en Artes y Pedagogía en Artes. La primera categoría se tituló “características y aportación del sentido pedagógico”, la cual responde a la pregunta ¿cómo se promueve el sentido pedagógico y qué genera? (ver Figura 1). La segunda categoría se tituló "agentes de cambio", esta responde a ¿quiénes promueven este sentido pedagógico? (ver Figura 1). Esta última categoría se nombró así porque estos grupos (no todos en la misma medida) son quienes activan el sentido pedagógico para generar nuevas aportaciones de las artes en los espacios sociales y en la formación crítica del estudiantado. La tercera categoría se tituló "dificultades", la cual se refiere a las situaciones que dificultan la promoción del sentido de lo pedagógico en dichas instituciones.

Ahora bien, es importante señalar que estas categorías no son fijas y se materializan a través de diversos elementos, ya que se entrecruzan con otros aspectos y sentidos. A su vez, estos nuevos sentidos no son 
expresados de forma individual y estática, sino que se articulan de forma dinámica y se cruzan entre sí, dotando de interrelaciones y profundidad al objeto de estudio.

A continuación, se presentan algunos resultados de la sistematización de los datos trabajados en las diez entrevistas a las autoridades académicas (ver Tabla 1 y Figura 1). Dichos datos se refieren solo a la primera y a la segunda categoría, en las que el sentido pedagógico se vuelve causa y efecto, y es promovido por diferentes actores/actrices en las universidades chilenas. En la Tabla 1, se observan las principales categorías de análisis. Por su parte, en la Figura 1, se muestra un mapa conceptual que permite visualizar la triangulación de los resultados encontrados.

\section{TABLA 1.}

Matriz de sistematización de categorías de análisis del sentido pedagógico en las autoridades académicas de carreras de Artes y Pedagogía en Artes en Chile

\begin{tabular}{|c|c|c|c|}
\hline $\begin{array}{l}\text { Experiencia } \\
\text { de estudio }\end{array}$ & Categoría & $\begin{array}{l}\text { Pregunta } \\
\text { orientadora }\end{array}$ & Códigos/Variables \\
\hline \multirow{9}{*}{$\begin{array}{l}\text { Sentido } \\
\text { pedagógico }\end{array}$} & \multirow{2}{*}{$\begin{array}{l}\text { Características y } \\
\text { aportación }\end{array}$} & $\begin{array}{l}\text { ¿Cómo se } \\
\text { promueve? }\end{array}$ & $\begin{array}{l}\text { Mediación artística } \\
\text { Imbricación social/comunidad } \\
\text { Reflexividad/pensamiento crítico } \\
\text { Lo relacional/colectivo }\end{array}$ \\
\hline & & ¿Qué genera? & $\begin{array}{l}\text { Aporte social } \\
\text { Transformación } \\
\text { Nuevas subjetividades }\end{array}$ \\
\hline & \multirow{3}{*}{$\begin{array}{l}\text { Agentes de } \\
\text { cambio }\end{array}$} & \multirow{3}{*}{$\begin{array}{l}\text { ¿Quiénes } \\
\text { promueven el } \\
\text { sentido } \\
\text { pedagógico? }\end{array}$} & Institución \\
\hline & & & Profesorado \\
\hline & & & $\begin{array}{l}\text { Estudiantado } \\
\text {. }\end{array}$ \\
\hline & \multirow{4}{*}{ Dificultades } & \multirow{4}{*}{$\begin{array}{l}\text { ¿Cuáles son los } \\
\text { impedimentos } \\
\text { de expansión } \\
\text { del sentido } \\
\text { pedagógico? }\end{array}$} & $\begin{array}{l}\text { Criterios Consejo Nacional de } \\
\text { Acreditación }\end{array}$ \\
\hline & & & $\begin{array}{l}\text { Aspectos curriculares de las } \\
\text { carreras }\end{array}$ \\
\hline & & & $\begin{array}{l}\text { Tipos de liderazgos y } \\
\text { profesorado en las carreras }\end{array}$ \\
\hline & & & Configuración del estudiantado \\
\hline
\end{tabular}

Fuente: Elaboración propia. 


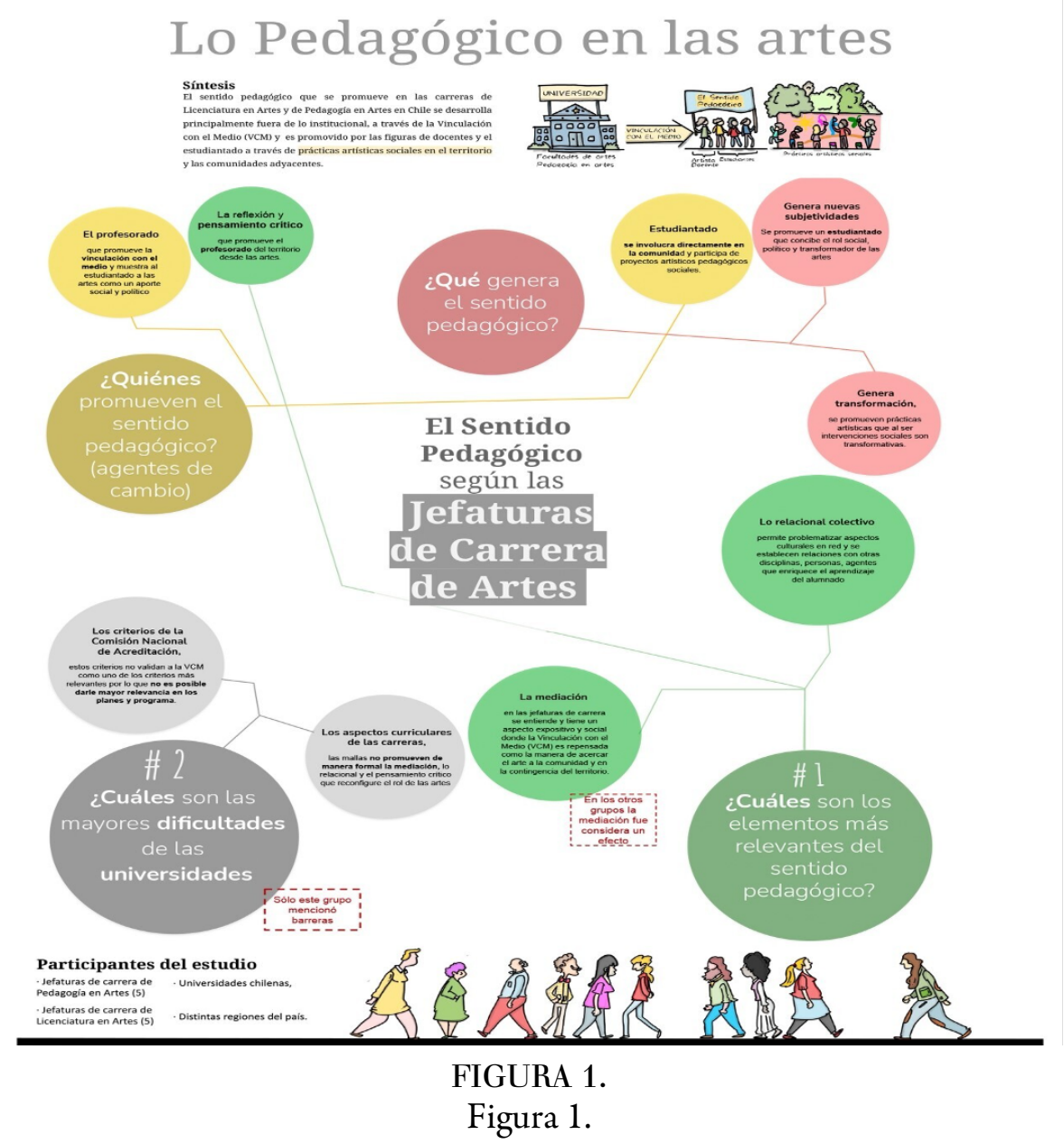

Conceptualización de resultados. Lo pedagógico en las artes: sentido pedagógico según las jefaturas de carreras de arte en Chile Fuente: Elaboración propia.

\subsection{Categoría: características y aportes del sentido pedagógico}

La primera categoría que emergió en los resultados alude a la pregunta ¿cómo se promueve el sentido pedagógico en las carreras de Artes y Pedagogía en Artes en Chile y qué genera en el estudiantado? Estos cuestionamientos llevaron a la identificación de una serie de elementos muy relevantes, que las autoridades de dichas carreras fueron relatando, sobre el propio funcionamiento de sus carreras, así como las experiencias que a ellos -como personas líderes de las carreras- les importan y buscan promover.

Lo primero que se evidenció, cuando a cada autoridad se le preguntó por el sentido pedagógico, fue que la mayoría lo identificaba con acciones que ocurrían fuera del contexto universitario, es decir, se referían a actividades que se organizaban desde la universidad, pero que eran realizadas en otros espacios físicos y con otras comunidades.

En dichas actividades que relataban las autoridades, expresaron la necesidad de imbricación social y afectiva con otras comunidades, a partir de un trabajo relacional y colaborativo y que, además, ocurría por un pensamiento crítico ante la concepción de las artes y su rol en la sociedad. Estos relatos llevaron a establecer la pregunta por la mediación artística y a entenderla como una práctica y metodología de trabajo desarrollada en la universidad para relacionarse con el medio. Con respecto a esto, se pudo identificar el concepto de mediación artística en los relatos que compartieron las jefaturas de carreras, pues, al preguntarles por las 
formas en que se promovía el sentido pedagógico en la carrera, constantemente se aludía a lo que en estas casas de estudios llaman vinculación con el medio (VCM) o extensión.

De acuerdo con lo anterior, VCM o extensión es una de las labores que obligatoriamente deben realizar las carreras y su profesorado para ser evaluados tanto en los procesos de acreditación como en la misma calificación académica docente. Las actividades de VCM o de extensión son formas de mostrar el compromiso con el entorno que les rodea y de generar un impacto social y cultural positivo, donde las imbricaciones sociales y el sentido de comunidad propician la vinculación como activador de sentidos.

En cuanto a aspectos normativos, el artículo n. ${ }^{\circ} 1$ de la Ley 21.091 Sobre Educación Superior menciona la importancia que posee la VCM para la educación chilena:

La vinculación con la comunidad a través de la difusión, valorización y transmisión del conocimiento, además del fomento de la cultura en sus diversas manifestaciones, con el objeto de aportar al desarrollo sustentable, al progreso social, cultural, científico, tecnológico de las regiones (Ministerio de Educación, Ley 21.091, 2018).

De igual manera, en el artículo n. 2 se menciona que "el Sistema, en particular a través del Sistema Nacional de Aseguramiento de la Calidad de la Educación Superior, fomentará la vinculación de sus integrantes con las necesidades de la sociedad" (Ministerio de Educación, Ley 21.091, 2018).

Tomando en consideración la importancia de la VCM tanto en los procesos universitarios como para el sistema de educación, aquí parece relevante mencionar, entonces, que el sentido pedagógico debe ser explorado y reconocido como una labor que ocurre de manera externa (VCM o extensión) y que, además, por las características de lo relatado, se relaciona con las prácticas de mediación artística.

Se han planteado diversas formas de entender la mediación artística desde un campo reciente. La primera forma de entenderla se relaciona con lo que el giro educativo (Rogoff, 2011) ha provocado en las instituciones culturales, ya que ha significado el planteamiento de diversas estrategias de curadurías y educación artística, con los objetivos de acercar las artes al público y, también, de plantear lo educativo como contenido en las muestras expositivas.

Una segunda forma de entender la mediación artística alude al "modelo de educación artística para la intervención social a través del arte" (Moreno, 2016, p. 17). Este autor plantea la mediación artística centrada en las prácticas artísticas y educativas, en las que las artes son una herramienta para la transformación social y la inclusión. Estas emergen del trabajo del arte comunitario que se comenzó a desarrollar en Norteamérica y Europa en los años setenta, cuando los artistas comenzaron a participar en diversos proyectos sociales.

Una tercera forma de entender la mediación artística es desde la perspectiva de Fontdevila (2018) quien menciona que el arte no solo es mediado por un agente externo, sino que en sí mismo es agente de mediación por su capacidad de condicionar e incidir en procesos asociativos y de agencia. Esta tercera forma entiende que la propuesta artística o producción es una experiencia que genera o deviene de una mediación.

Las tres formas de mediación planteadas estarían relacionadas con diversos agentes. En el primer caso, sería la institución cultural quien promovería la mediación a través de su programación. En el segundo, es el artista o los colectivos de artistas a través del desarrollo de prácticas artísticas en comunidades, lo que también se ha llamado arte relacional (Bourriaud, 2017), arte colaborativo (Rodrigo y Collados, 2014), arte comunitario, desarrollo social comunitario, (Moreno, 2016), entre otros. La tercera vía es el arte en sí mismo (la creación o producción artística), la cual genera mediación entre agentes humanos y no humanos.

Si se trasladan estas tres formas de mediación y se vinculan con los relatos de las jefaturas de carreras que participaron del estudio, se alude al sentido pedagógico como un aspecto netamente expositivo y social, en el que la VCM es repensada como la manera de sacar al arte del espacio universitario cerrado (talleres) para acercarlo a la comunidad y al territorio.

En los siguientes relatos se puede reflexionar acerca del sentido que tiene para las autoridades lo pedagógico y cómo emergen elementos de la mediación artística comprendida desde la VCM y la imbricación social con el territorio y las comunidades: 
Trabajamos muchas veces para la comunidad, entonces, por ejemplo, la realidad es tema para nosotros (...) la deforestación, la minería, los problemas de marginación (...) En los talleres lo trabajamos también, y finalmente hay un enlace con lo que está aconteciendo, y, en ese sentido, la capacidad de comunicar de nuestros estudiantes está en el encuentro con la comunidad, en ese tema -digamos- en esos campos. Sobre todo, cuando vamos a terreno, cuando exponemos en la calle, ese tipo de cosas (Autoridad académica 3, Licenciatura en Artes, videollamada, 7 de abril de 2020).

Desde la otra vereda, hay una recepción de información que tiene que ver con las artes visuales muy grande, y ahí se producen muchas instancias de mediación. La de este año, que se postergó hasta principio de marzo -por todo lo que ha pasado en el país- por lo mismo, por las características que tuvo se realizó casi la mitad de las exposiciones en una plaza como un acto de hacer arte público y de estar como vinculándose con lo que está pasando en el país, y se llenó de gente (Autoridad académica 7, Licenciatura en Artes, videollamada, 27 de abril de 2020).

Si un profesor lo promueve ellos lo hacen muy entusiastamente y participan súper bien, de hecho, yo misma tuve una exposición de arte indumentaria en la comuna de El Bosque, con un taller mío de arte textil y súper bien recibido por la comunidad, los estudiantes se entusiasman (Autoridad académica 5, Licenciatura en Artes, videollamada, 21 de abril de 2020).

Ahora, nosotros lo abordamos de distintos lugares, la carrera tiene cierta tendencia a la mediación, entonces está muy relacionado lo artístico, como una herramienta de acercamiento del estudiantado a este mundo, a través de un puente que es la mediación (Autoridad académica 4, Pedagogía en Artes, videollamada, 10 de abril de 2020).

Como se observa, para la mayor parte de las autoridades académicas de las carreras de Licenciatura en Artes, el sentido pedagógico está centrado en las acciones de VCM. A través de las imbricaciones sociales y el sentido de comunidad, buscan darle sentido a la experiencia artística-pedagógica de manera conectada con el contexto sociocultural. Por un lado, se puede observar que, en los cuatro casos, se plantea la mediación artística como acciones que buscan acercar las artes a los diversos públicos a través de muestras expositivas y se enseña a otras comunidades el quehacer artístico del estudiantado y profesorado. Por otro lado, también se desarrolla una mediación artística a partir de acciones formativas que, en formatos de taller, se entregan a las comunidades. En este segundo caso, las artes son promovidas como herramienta social para trabajar con diversos grupos.

También llama la atención que los problemas sociales sean la realidad espejo que el profesorado toma como punto de partida para el desarrollo de talleres y actividades para, de esta manera, generar un vínculo con las comunidades desde el quehacer artístico que se propone al estudiantado. Estas formas de enseñar las artes a los futuros artistas se vinculan con la idea de unas artes socialmente comprometidas, en las que el artista sale de su taller de creación individual para crear un sentido de intersubjetividad. Este modo de mostrar las artes al estudiantado se vincula con lo que Bourriaud (2017) ha expresado sobre las prácticas artísticas contemporáneas, en el que "el arte actual muestra que sólo hay forma en el encuentro, en la relación dinámica que mantiene una propuesta artística con otras formaciones, artísticas o no” (p. 22). Estas ideas llevan a pensar en la forma en la que el estudiantado aprende las artes desde acciones múltiples, en las qu el artista es productor de artes, docente de un taller o actividad, expositor en la plaza, etc.

Trabajar para el territorio y las comunidades, con ellos y desde este lugar genera reconfiguraciones del sentido de la práctica artística y una pertinencia que da compromiso social a las prácticas fomentadas en el estudiantado de artes. "La realidad es tema para nosotros" menciona la primera autoridad académica y con esto quiere decir que la realidad social se procesa y se repiensa desde el arte, lo que recuerda que no se pueden comprender los comportamientos artísticos si no se entiende la situación de los artistas (Bourriaud, 2017), eso que les afecta.

Lo social y contingente es enseñado al estudiantado de artes para que lo aprendan como un compromiso y una configuración profunda en su hacer como artista en el mundo. Desde esta perspectiva, se desprende que el profundo sentido social y mediador es el sentido pedagógico que se enseña en las carreras de artes, pues:

(...) transmitirle mediante asignaturas específicas; tenemos una que se llama gestión cultural (...) y en esos programas introducir estos contenidos políticos, críticos, comunitarios, territoriales y llevarlos a la realidad más tempranamente (...) Tenemos una asignatura que se llama Arte, Territorio y Contexto, yo acabo de hacer un ajuste curricular y la puse ahí, justamente para eso. Yo creo que es el gran aporte que tenemos ahora, porque ahí están obligados a responder a un contexto (Autoridad académica 9, Licenciatura en Artes, videollamada, 30 de abril de 2020). 
(...) Creemos que muchas de las reflexiones que van a salir antes de la producción de una obra o de su motivación de la obra [refiere a la obra que hace el estudiantado], también va a estar muy vinculado y con mucha raíz de lo social, y en ese sentido, habría que revisar las obras del Extramuro [sala de exposición del estudiantado perteneciente a la universidad], que creo que es una muestra bastante evidente de lo que te estoy contando. La mayor parte de estas obras están vinculadas a aspectos de la sociedad que nosotros podemos identificar como que son, no problemáticos, pero que son temas a atender (...) hay mucho trabajo acerca de las diversidades, mucho trabajo acerca de las desigualdades sociales, de género (...) y como por ejemplo, los temas sociopolíticos también está muy cruzado dentro de las temáticas sociales del estudiantado, yo diría que $100 \%$ de esa obra es sumamente sociocrítica, de una postura, reflexión y punto de vista, muy crítica de la sociedad que le toca vivir al estudiante al día (Autoridad académica 2, Pedagogía en Artes, videollamada, 2 de abril de 2020).

En los relatos que cuentan estas autoridades se muestra la importancia de dar lecturas críticas al aprendizaje de las artes, desde la reflexión y el pensamiento crítico social, como postura onto-epistemológica de artistas y artistas-docentes en formación. Por otro lado, se promueve la imbricación social del estudiantado en el contexto donde se desenvuelve su quehacer artístico-pedagógico.

En los relatos, se pueden identificar dos aspectos interesantes. Primero, se entiende el sentido de lo pedagógico como la promoción de un tipo de arte comprometido con su contexto y los problemas sociales. En segundo lugar, esto muestra que lo pedagógico puede ser un camino institucional, puesto que se promueven desde asignaturas que son parte de la malla curricular y desde espacios expositivos universitarios.

Según lo relatado, al estudiantado se le enseña el sentido pedagógico de las artes ligado a la mediación artística trabajada en las prácticas artísticas colaborativas y de intervención sociopolíticas. A través de estos aprendizajes, los futuros artistas aprenden el compromiso social desde las artes, la necesidad de responder al contexto y la posibilidad de generar transformación impulsando nuevos saberes, mediante una propuesta cultural que puede impulsar cambios sociales (Acaso y Megías, 2017).

En sintonía con la lectura de los lenguajes territoriales imbricándose con el medio, desde una perspectiva crítica, está el aspecto relacional y colectivo. Dicho aspecto, desde la producción colectiva o relacional, permite problematizar aspectos culturales en red y se establecen relaciones con otras disciplinas/personas/ agentes, lo que enriquece el aprendizaje del alumnado en sintonía con el simbolismo del territorio (Rodrigo y Collados, 2014). En consonancia con lo anterior, las autoridades entrevistadas afirman:

Es graficarte que desde que ellos están en etapa formativa (...) están en esta relación entre exponer, entre vincularse con otras comunidades de expositores que precisamente son artistas visuales (...) que se vincula entre el arte, la artesanía el diseño y entonces confluyen áreas que conllevan a relacionarnos con otro tipo de creadoras (...) es interesante de pensar, de cómo nos relacionamos con otros grupos de creadores. Ese tipo de cosas se realizan desde que están en la etapa formativa (Autoridad académica 10, Pedagogía en Artes, videollamada, 30 de abril de 2020).

(...) con las tejedoras de Quilen, de Chiloé, entonces ellas venían y nuestras estudiantes le mostraban lo que hacíamos, ellas nos enseñaron a hilar, tuvimos jornadas de trabajo de esa manera, y de esa manera, y como te digo siempre están pensándose actividades de esa manera desde adentro hacia afuera y de afuera hacia adentro. Eso es parte orgánica que siempre está moviéndose dentro de la malla curricular y de las actividades que tenemos (Autoridad académica 5, Licenciatura en Artes, videollamada, 21 de abril de 2020).

De acuerdo con ambas citas, se evidencia que las acciones promovidas desde VCM son espacios de mediación artística, donde el estudiantado va adquiriendo compromisos políticos y se ven como posibilitadores de cambio social en sus contextos (García-Huidobro y Schenffeldt, 2020).

Entonces, el sentido pedagógico puede ser comprendido como un encuentro de experiencias, historias y narrativas, las cuales el estudiantado aprende a trabajar fuera del espacio universitario. Además, se constituye como un proceso de aprendizaje y transmisión de conocimientos de manera conjunta y recíproca que el estudiantado conforma de acuerdo con sus preocupaciones sociales, en el que la práctica cultural y la mediación se conectan con otros saberes; a raíz de esto, se conforman colectividades heterogéneas a favor de la generación de conocimiento (García-Huidobro y Montenegro, 2021).

Lo relacional es, sin duda, un elemento fundamental en la forma en la que las carreras artísticas muestran a los futuros artistas su despliegue en sociedad, para que no entiendan su hacer en tanto producción de objetos 
artísticos, sino como posibilitadores de realidades y donde, más que actuar como personas aisladas, asuman una posición (Velasco, 2015) y más que ser inventores, sean mediadores.

\subsection{1 ¿Quégenera el sentido pedagógico?}

Como se mencionó anteriormente, el sentido pedagógico es causa y efecto, y se entrecruza con más elementos que nutren y potencian todas sus formas. Además, el sentido pedagógico genera efectos relevantes en la forma en la que se enseñan las artes, en la forma en la que el estudiantado se apropia de las prácticas artísticas y en la manera de la enseñanza vinculada con lo social. Estas observaciones, dentro de la primera categoría de análisis, llevaron a la comprensión de que el sentido pedagógico, promovido en las carreras de Licenciatura en Artes y Pedagogía en Artes a través del profesorado y del estudiantado, genera aporte social, nuevas subjetividades y posibilidades transformativas. Esto se pudo observar porque las formas de enseñanza que se vinculan con lo social apuntan al rol emancipador del arte (Guerra, 2017), lo que permite repensar el conocimiento artístico. Este sentido social del estudiantado y del profesorado de artes se ha convertido en una práctica política cotidiana:

(...) en un proyecto artístico donde están influyendo sus intereses personales y sus dramas, efectivamente el arte se vuelve un proceso sanador y en algún momento esa mirada narcisista o egocéntrica en muchos casos, a sus propias problemáticas, lo vuelve algo compartido con muchas personas que están también viviendo lo mismo y entienden ahí el potencial de intervenir la realidad y de potenciar el arte propiamente tal. Eso se vuelve en sí mismo como una experiencia de aprendizaje, como herramienta transformadora (Autoridad académica 3, Licenciatura en Artes, videollamada, 7 de abril de 2020).

Este relato expresa dos formas en las que el sentido pedagógico, promovido en las artes, es un aporte social para el estudiantado, quienes lo viven y lo aprenden y luego lo pueden llevar a otros contextos de acción de la misma manera en la que lo experimentaron. Asimismo, la autoridad académica narra que el estudiantado aprende las artes como un proceso sanador de sí mismo y de otros(as), lo que, además, pueden compartir con otras personas en esos espacios de enseñanza y aprendizaje. En esta situación, se puede ver que el arte se promueve como una herramienta transformadora, en la que interviene como un agente mediador (Moreno, 2016) de sí mismos y, también, con relación a otros en un espacio de aprendizaje mediado.

Es preciso reiterar que la transformación social no es comprendida como grandes sucesos que cambiarán radicalmente el entorno/contexto/territorios, sino que, como explica Atkinson (2016), es la fuerza del arte lo que impulsa la generación de nuevos saberes que en sí mimos ya son transformativos. De esta manera, aquí es donde se refleja el potencial del arte como sanador de procesos personales, canalizador y catalizador de posturas y decisiones políticas que se verán reflejadas en el quehacer artístico-pedagógico del estudiantado. La transformación no es entendida como un gran cambio en un espacio singular, sino como la posibilidad de abrir nuevas respuestas contextuales mediante una propuesta cultural y de aprendizajes continuos.

En el relato se entrecruzan las nuevas subjetividades y la transformación social como una nueva posibilidad desde lo artístico. En este sentido, la práctica artística se describe como un espacio crítico y creativo que contempla otras formas de pensar y comprender el quehacer artístico (Sullivan, 2010), en el que se vinculan aspectos sociales desde la enseñanza y desde lo social para la enseñanza (Daichendt, 2010). La "herramienta transformadora" que menciona la autoridad académica reafirma los valores sociales de las carreras del ámbito artístico y enriquecen la formación, lo que abre la posibilidad a nuevas propuestas de impacto en lo social (García-Huidobro, 2019).

Como se verá, las nuevas subjetividades y la transformación -como nueva posibilidad desde lo artísticoen los relatos de las autoridades académicas van generando cruces con otras propuestas que robustecen la noción del sentido pedagógico, tales como la reflexividad/pensamiento crítico y las imbricaciones sociales:

(...) cuando un estudiante desarrolla la práctica, buscamos siempre que la práctica esté asociada a un taller, porque ahí va dando un espacio extra, como ha ocurrido también que dentro de la malla curricular, la primera práctica, esa que se hace en 
segundo año, fuese una práctica de taller, pero vinculado a una problemática que tenga esa comunidad, entonces desde el principio entender (...) el por qué hacemos esto; un taller dentro de un colegio (...) lo hacemos no para gastar tiempo, si no para resolver esas problemáticas que no pueden ser resueltas de otras maneras, porque son lenguajes que involucran una escala de valores, preocupaciones y de sensibilidades que no están presentes dentro de los otros sectores (Autoridad académica 1 , Pedagogía en Artes, comunicación personal, 6 de febrero 2020).

(...) dentro de esas prácticas progresivas hay algunos que les interesa el área social (...) y no eligen un establecimiento de educación formal, sino que se van a hacer la práctica progresiva a un aula hospitalaria, a un centro de día, tuvimos a una chica en un centro psiquiátrico o en la pinacoteca (...) entonces son diferentes maneras de llegar a un público distinto (Autoridad académica 8, Licenciatura en Artes, videollamada, 29 de abril de 2020).

Las nuevas subjetividades, según Aguirre (2005), se vinculan con las experiencias contingentes que permiten repensar la experiencia, donde lo artístico levanta nuevas comprensiones en primera persona. En las citas anteriores, estas comprensiones que el estudiantado debe ir haciendo para construir su identidad en las artes están estrechamente ligadas a entendimiento del espacio socioeducativo. El entender por qué hacemos esto, como menciona la autoridad académica de Pedagogía en Artes, es transformar sus propias configuraciones del territorio desde una perspectiva crítica. Esto luego les permite generar nuevas lecturas de la realidad, que enfatiza en el potencial de la educación artística y alude a esas sensibilidades ausentes en otros lugares, como un potencial engranaje que poseen las artes para reivindicar la diversidad del territorio desde la cultura visual (Huerta, 2014). En ambos casos relatados, pareciese que las artes son presentadas al estudiantado como una herramienta de intervención que debe ponerse en juego en contextos sociales. Ante este tipo de mediaciones, tanto el estudiantado de Licenciatura en Artes como Pedagogía en Artes aprende un rol como agente de cambio, al posibilitar nuevas realidades desde el quehacer artístico:

(...) el estudiantado va adquiriendo, a lo largo de su formación, una significación de la educación artística como derecho del estudiantado (...) en ese sentido, nosotros hemos intentado ser muy críticos del sistema, para que el estudiante se empodere de esta situación y que en su práctica vaya siempre intentando ganar lugares (Autoridad académica 6, Pedagogía en Artes, video llamada, 22 de abril de 2020).

Promover la idea de la persona artista-docente concienciada socialmente rompe el mito del artista genio (a), productor de artes en un taller, o bien el mito de la pedagogía que solo transmite conocimientos que forman parte de un proceso de aprendizaje formal, definido e institucionalizado. La invitación que esta autoridad académica propone al alumnado en el relato anterior es a transformar sus subjetividades y convertirse en agentes de cambio, empoderarse de su práctica artística-docente, en otras palabras, se trata de una "repolitización de una práctica instituyente (...) en la medida que vuelven porosos los muros de las instituciones” (Rodrigo y Collados, 2014, p. 68).

\subsection{Categoría agentes de cambio, ¿quiénes promueven el sentido pedagógico?}

La segunda categoría que emergió en este estudio se denomina "agentes de cambio", puesto que alude a los colectivos que promueven el sentido pedagógico en las carreras de Licenciatura en Artes y Pedagogía en Artes en Chile. En este escenario, se logró distinguir tres actores clave: institución, profesorado y estudiantado, quienes encarnan el sentido pedagógico.

En el análisis se evidenció que la institución, a través de la malla curricular, promueve escasamente el sentido de lo pedagógico como nuevas posibilidades para el profesorado y el estudiantado. Si bien se reflejan esfuerzos, son otros los principales agentes de cambio que promueven y reclaman la expansión de los sentidos de lo pedagógico. Las casas de estudio resguardan el statu quo en las formas de enseñar y aprender permiten poco espacio curricular para incorporar nuevas subjetividades y transformaciones.

Archer (2009) refiere a los problemas de la estructura y la agencia, donde se experimentan tensiones entre estos condicionamientos estructurales y los poderes agenciales (Chernilo, 2009). Esto es precisamente lo que se observó en el análisis de los relatos, pues se apreció que las tensiones y los procesos de agenciamiento para 
repensar el arte en las instituciones educativas eran promovidos por el profesorado y el estudiantado. Por su parte, las instituciones no llegan a absorber esos procesos, ya que las acciones que no están formalizadas no son valoradas y tienen menor cabida de validez institucional en los procesos de formación y enseñanza en las carreras de arte en Chile. Por otro lado, hay espacios reconocidos por la institucionalidad, por ejemplo, la VCM, los cuales son propicios para generar y posibilitar nuevos lugares para experimentar el conocimiento con capacidad disruptiva en el sistema y desde ese espacio se activa el sentido pedagógico.

En las siguientes citas se verá la manera en la que el profesorado y el estudiantado promueven el sentido pedagógico desde diferentes espacios, los cuales se abren en la contingencia para dotar a la experiencia de aprendizaje de un sentido más amplio. A saber, el profesorado menciona:

Claro, mira, nosotros con los chicos, a parte las clases, hacemos mucha vinculación con el medio con respecto a diferentes tipos de artesanos, con artistas que hacen otras técnicas y que están relacionadas con las asignaturas que están haciendo. Por ejemplo, el año pasado, el electivo de cerámica fue a visitar a un ceramista de Penco y fueron a ver las obras que él hacía. Es interesante eso también, poder vincularse y cómo esto se lleva a cabo en diferentes instancias que no son el aula (Autoridad académica 6, Pedagogía en Artes, videollamada, 22 de abril de 2020).

Por ejemplo, una actividad que funciona súper bien y que fue a través del curso de artes medievales con dos profesores fue una actividad que ellos hicieron como de activar (...) van treinta estudiantes a tomarle fotos a un lugar (...) como "Las memorias del olvido" [nombre de la actividad] y ahí nos dimos cuenta de que con estos talleres ellos pudieron activarlos llenos, completos. Los mismos estudiantes asistieron, de alguna manera en un contexto bastante complejo [por el contexto del Estallido social en Chile], tuvieron que repetir el taller en dos oportunidades (Autoridad académica 8, Licenciatura en Artes, videollamada, 29 de abril de 2020).

Como se observa, en ambos casos, el profesorado es un agente que insta al estudiantado a desarrollar actividades de creación, las cuales son relacionales y sociales y las experiencias de aprendizaje ocurren desde la mediación. Fueron numerosos los relatos en los que se destacó la labor y el esfuerzo que realiza el profesorado al promover actividades que sacan del taller al artista o pedagogo en artes en formación para que aprenda a ser artista desde el compromiso social, lo relacional y colaborativo.

Estas ideas recuerdan el espacio pedagógico que propone Atkinson (2015), el que surge desde la aventura de compartir. Este autor alude a la experiencia de aprendizaje como un viaje en el que todo el grupo va siendo, aprendiendo y descubriendo de manera relacionada. A esto, él lo llama subjets yet to come. Esta forma de enseñar las artes posibilita acciones de agenciamiento, ya que detonan procesos de emancipación y subjetivación. Así, la experiencia artística pedagógica se transforma en acciones y espacios que abren nuevas posibilidades del imaginario de los artistas y también el de los estudiantes ante las artes.

Por otro lado, es importante mencionar que el profesorado valora positivamente la libertad que posee para realizar sus cátedras, pues pueden transmitir nuevas propuestas y sentidos al estudiantado. Se observa, en el caso de la autoridad académica de Pedagogía en Artes, que la formación artística es relevante dado que "enfatiza la creación y experiencia de obras de arte visuales por sus valores intrínsecos" (Smith, 2004, p. 2), y aporta al alumnado la realidad de ser artista y producir arte al otorgar una experiencia de la forma en la que se vive el arte en primera persona (Atria, 2015).

En segundo lugar, está el relato de una autoridad académica de Licenciatura en Artes, quien narra cómo el profesorado crea espacios para aprender las artes desde situaciones contingentes, tal es el caso del Estallido social en Chile durante el $2019^{2}$, como una experiencia propositiva para imbricarse en el territorio y la contingencia social. Estas formas de enseñar las artes, como una forma de reflexión artística sobre lo que ocurre social y políticamente, son pedagógicas, puesto que invitan al estudiantado a emprender posibilidades de aprendizajes y experiencias del arte que aportan nuevas miradas subjetivas sobre cómo se vive una compleja situación social.

Estas maneras se vinculan con el activismo artístico. En Latinoamérica, el activismo artístico estuvo marcado por su resistencia a la dictadura, donde la actividad artística evidenció la limitación de las libertades. A partir de la dictadura militar en Chile, muchas de las acciones de artistas y colectivos buscaron visibilizar lo negado, primero, a través de lo que ocurría con el régimen político represivo y, luego, con los gobiernos 
democráticos. En el caso que se relata, se observa que el profesorado cumple un rol importante para el estudiantado durante el Estallido social, en cuanto son referentes que muestran el rol político de las artes y la forma en la que el estudiantado puede agenciarse en ello.

En este terreno, se observa que las actividades que desarrolla el cuerpo docente de las carreras de Licenciatura en Artes y Pedagogía en Artes son altamente concurridas, puesto que el estudiantado también posee un interés político y social a la hora de aprender las artes y hacer sus propuestas personales. En este sentido, se apreció que el estudiantado también es un agente de cambio relevante, pues, a partir de sus intereses, promueve el constante desarrollo de prácticas artísticas críticas de mediación, colaborativas y contextualizadas:

Hay muchos estudiantes que trabajan con agrupaciones indígenas, que descubren sus propios linajes originarios y que trabajan en comunidades que también tienen que ver con una reflexión política sobre las minorías, si son o no escuchados (...) son espacios donde hay que levantar discursos y es relevante levantar esas problemáticas (...) Entonces, lo veo un montón con estudiantes que trabajaron en sus territorios con problemáticas mucho más contemporáneas, habitacionales, territoriales en cuanto a la conformación de las casas, la división de la vivienda, como se constituye la manera de vivir en esos lugares, y levantando la información desde la comunidad, levantando encuestas, mandando una carta, levantando las obras a partir del trabajo comunitario (Autoridad académica 7, Licenciatura en Artes, videollamada, 27 de abril de 2020).

Ahora, yo no sé si la carrera lo promueve como tal [refiere al sentido pedagógico], sino que nos hemos ido dando cuenta claro, también hay un tema generacional que tiene que ver con el momento histórico que nos tocó vivir- son estudiantes que en el 2011 estaban en enseñanza básica, pasando a la [educación] media, están motivados por una etapa social súper movida, entonces son estudiantes que tienen cierta opinión, por lo tanto, tienen un sentido social súper desarrollado y no se pueden restar de eso (Autoridad académica 4, Pedagogía en Artes, videollamada, 10 de abril de 2020).

Tanto estos relatos como otros provenientes de distintas autoridades de las carreras de Licenciatura en Artes y Pedagogía en Artes muestran el rol protagónico que posee el estudiantado en la búsqueda y el desarrollo de prácticas artísticas que se alejan de la autonomía del arte y la obra en sí misma como objeto cosificado y se sitúan en un contexto específico; el que les afecta social, política, cultural y económicamente. Este tipo de prácticas artísticas se ubican en el llamado arte contextual (Del Río-Almagro, 2015) y arte comunitario (Moreno, 2016) y toman como origen el contexto de localización sociocultural y político.

La conciencia política del estudiantado los lleva constantemente a ser agentes de cambio en potencia, puesto que poseen la inquietud por el desarrollo de otro tipo de prácticas artísticas, unas que buscan dar:

Forma a proyectos y espacios de colaboración para responder a necesidades contextuales concretas mediante la puesta en práctica de medios culturales diversos con los que transformar situaciones conflictivas determinadas, produciendo con ello un cambio social encaminado a promover una transformación -mediante aprendizajes continuos- de los propios agentes sociales y culturales implicados (Rodrigo y Collados, 2014, p. 59).

Este tipo de prácticas colaborativas y relacionales enseñan un sentido pedagógico, por cuanto son propuestas que permiten generar efectos transformativos en los espacios que se desarrollan.

\section{Discusión}

En este escrito se ha enseñado parte de los resultados de la investigación Fondecyt 11180057, la cual busca comprender la forma en la que los artistas y artistas-docentes incorporan elementos pedagógicos en su quehacer artístico. Esto ha llevado a la observación de los cruces entre las artes y lo educativo de diversos grupos. En el presente escrito, se ha revisado cómo esto se promueve en las carreras de Licenciatura en Artes y Pedagogía en Artes chilenas, en las que el estudiantado y el profesorado son agentes que constantemente están generando acciones de transformación desde lo artístico hacia las comunidades y que dotan de sentido pedagógico a las prácticas artísticas. El profesorado será quien entienda cuáles son los valores del arte fomentados en las instituciones formativas y si estas muestran las nuevas formas de pensar en las artes que ha instalado el fenómeno del giro educativo. 
¿Cómo estas carreras promueven lo pedagógico en la enseñanza de las artes? Parece fundamental analizar que lo pedagógico es comprendido, por la totalidad de las carreras, como un pensar y un hacer que va más allá de la propia enseñanza y la transmisión de contenidos artísticos, lo cual enseña que es posible cuestionar el modelo del arte basado en la individualidad y el éxito de la producción artística. Con relación a ello, Hernández (2011) ha explicado:

La formación en la universidad favorece el individualismo. Este enunciado adquiere carácter de máxima en una facultad como la de Bellas Artes donde la idea de 'artista', 'diseñador', 'fotógrafo' está marcada por la obligación de ser 'autor'. Si fracasa el proyecto de ser autor, se cae todo el andamiaje del discurso en torno a formación que se propone desde la facultad. Pero ser autor individual, no como parte de un proyecto que se lleva a cabo con otros. A veces los estudiantes tratan de quebrar esta obsesión (p. 88).

Dichas palabras son importantes para expresar el importante rol que juega tanto el estudiantado como el profesorado para romper con dicho individualismo, puesto que ambos grupos enseñan un compromiso social con las artes. Surge, entonces, la mediación, lo relacional/colectivo, la reflexividad y la imbricación social como elementos del sentido pedagógico para estas carreras, pues las autoridades aluden a estos cuatro elementos como nuevos espacios para el conocimiento y, además, son los que promueven el acto de enseñar y aprender.

Parece preocupante, igualmente, que en la mayoría de los relatos que refieren a lo pedagógico se expresa como acciones que ocurren fuera del espacio universitario y son situados como VCM. Se cree que esto levanta el desafío de crear mayores esfuerzos por reconocer qué parte del trabajo artístico colaborativo y crítico generado en el interior del espacio universitario también es pedagógico, por cuanto promueve relaciones significativas.

En cualquier caso, se debe precisar el hecho de que, en las formaciones artísticas, el sentido pedagógico desarrollado en las artes, y a través de esta área, dentro de un contexto universitario o eterno a este, siempre será político, ya que son experiencias en las que se genera algo nuevo y civilizador. Esto le muestra al estudiantado su rol como artista y artista-docente que lo compromete con la sociedad (o socialmente). Se observa que las formaciones ofrecen a sus estudiantes nuevas posibilidades disruptivas de generar cambios en los espacios desde las artes (Guerra, 2017), algo que más que un discurso político para trabajar en clases supone acciones directas y acumulativas con potencialidades de cambio.

Por último, cuando se habla de promover nuevos significados, se refiere a una postura política en la que las personas productoras de cultura se transforman en agentes politicos(as) que promueven el cambio social (Mörsch, 2015). Los agentes de las formaciones artísticas enseñan la necesidad de producir cambios y de ir más allá de lo propositivo en el arte, para promover prácticas artísticas y culturales que sean socialmente transformadoras y un motor de cambio social (Acaso y Megías, 2017). En el caso de la academia, que es un espacio del sistema de educación formal cuyo conocimiento y relaciones están institucionalizadas, lo artístico surge como una capacidad para 'algo', es una acción o actividad que, como señalan Gil y Calderón (2018), produce algo nuevo que se pone al servicio de la ciudadanía y los agentes de cambio para propiciar cambios en las lógicas y lenguajes territoriales (Sales et al., 2019).

Desde las mismas comunidades, territorios y tejidos sociales, que modelan al estudiantado de artes, emergen procesos reflexivos desde el hacer artístico que, situados e imbricados desde los mismos problemas de la comunidad y el territorio, se transforman en el cimiento de las personas agentes de cambio. Esto dota de nuevos significados que generan sentido a las comunidades, situándolos como posibilitadores de vida $\mathrm{y}$ cultura y, desde aquí, emergen las transformaciones sociales (García-Huidobro y Schenffeldt, 2020), cuyas producciones culturales no solo se consagran a lo artístico como técnica o contenido, sino con preguntas, problemas, cuestionamientos, nuevos sentidos y posicionamientos. 


\section{Agradecimientos}

Se agradece a la Agencia Nacional de Investigación (ANID), al Fondo Nacional de Ciencia y Tecnología (FONDECYT) y a la Universidad de los Lagos como instituciones patrocinadoras del estudio Nuevos vínculos y desafíos entre lo artístico y lo pedagógico. Abriendo campos hacia una re-conceptualización del arte y el rol del/la artista en la sociedad actual.

\section{Referencias bibliográficas}

Acaso, M. y Megías, C. (2017). Art Thinking. Cómo el arte puede transformar la educación. Paidós.

Aguirre, I. (2005). Teorias y prácticas en educación artística. Ensayo para una revisión pragmatista de la experiencia estética en educación. Octaedro.

Archer, M. (2009). Teoría social realista. El enfoque morfogenético. Ediciones Universidad Alberto Hurtado.

Atkinson, D. (2015). The adventure of pedagogy, learning and the not-known. Subjectivity 8(1), 43-56. https://doi. org/10.1057/sub.2014.22

Atkinson, D. (2016). Without Criteria: Art and Learning and the Adventure of Pedagogy. International Journal of Art \& Design Education, 36(2), 141-152. https://doi.org/10.1111/jade.12089

Atria, M. (2015). Paradojas de la educación artística en la universidad. En C. Herrera y N. Richard (Eds.), Escuelas de Arte, Campo Universitario y Formación Artística (pp. 103-110). Universidad de Chile.

Badiou, A. (2002). Deleuze: El clamor del ser. Manantial.

Barone, T. y Eisner, E. (2006). Arts-Based Educational Research. En J. Green, G. Camilli y P. Elmore (Eds.), Handbook of Complementary Methods in Education Research (pp. 95-109). Routledge.

Bourriaud, N. (2017). Estética relacional. Adriana Hidalgo Editora.

Cercós i Raichs, R. (2017). El pensamiento estético-pedagógico de Joseph Beuys: entre la memoria y la performance. Historia y Memoria de la Educación 5, 217-237. https://doi.org/10.5944/hme.5.2017.16797

Chernilo, D. (2009). Introducción del traductor. En M. Archer (Ed.), Teoría social realista. El enfoque morfogenético (pp. 4-13). Ediciones Universidad Alberto Hurtado.

Daichendt, J. (2010). Artist-teacher: A Philosophy for Creating and Teaching. Intellect Books.

Del Río-Almagro, A. (2015). Posturas en la antesala de la investigación y creación artística. En A. Collados y J. Rodrigo (Coords.), Transductores 3. Pedagogias colectivas y politicas espaciales (pp. 29-38). Centro José Guerrero.

Deleuze, G. (1990). Negotiations, 1972-1990. Columbia University Press.

Delgado, M. (2013). Artivismo y pospolítica. Sobre la estetización de las luchas sociales en contextos urbanos. Quaderns-e de l'Institut Català d'Antropologia, 18(2), 68-80.

Expósito, M., Vindel, J. y Vidal, A. (2012). Activismo artístico. En M. Tapia y M. Pineda (Eds.), Perder la forma bumana. Una imagen sísmica de los años ochenta en América Latina (pp. 43-50). MNCARS.

Fontdevila, O. (2018). El arte de la mediación. Consonni.

García-Huidobro, R. (2019). Prácticas y producciones artísticas que se re-significan desde lo pedagógico. Revista Estudios Sobre Arte Actual, (7), 211-217.

García-Huidobro, R. y Montenegro, C. (2021). El proceso de mediación en los proyectos pedagógicos. Artistasdocentes como creadores-as de relación a través de las artes. Revista Colombiana de Educación 1(82), 83-106. h ttps://doi.org/10.17227/rce.num82-10587

García-Huidobro, R. y Schenffeldt, N. (2020). Subjetividades del profesorado de artes y su rol como agentes/as de cambio. Revista internacional para la justicia social 9(2), 173-195. https://doi.org/10.15366/riejs2020.9.2.009

García-Huidobro, R. y Schenffeldt, N. (en prensa). El método de taller artístico de discusión para investigar la experiencia de artistas-docentes en la era postcualitativa. Artnodes. Journal on Art, Science and Technology. 
Mg(c). Ninoska Schenffeldt Ulloa, et al. El Sentido pedagógico de las artes en las carreras de Lic...

García-Huidobro, R., Viveros-Reyes, F. y Bahamonde-Courbis, G. (2020). Creaciones y transformaciones en la ontoepistemología de los(as) artistas-docentes. Un proyecto al sur de Chile. Arte, individuo y Sociedad 32(3), 661-677.

Gil, J. y Calderón, N. (2018). Arte, creación e investigación. Sobre el proceso creativo en el arte. En N. Calderón y J. Ortiz (Eds.), Practicar la inestabilidad. Diálogos y acercamientos desde la investigación artística (pp. 161-182). Universidad Veracruzana.

Guerra, L. (2017). De la inexistencia del arte. Brumaria.

Hernández, F. (2009). ¿De qué hablan los artistas cuando realizan proyectos artísticos-pedagógicos? En R. Parramón (Coord.), Acciones irreversibles (pp. 299-309). Eumo editorial.

Hernández, F. (2011). Pensar la relación pedagógica en la universidad desde el encuentro entre sujetos, deseos y saberes [Tesis doctoral, Universidad de Barcelona]. Repositorio Institucional. http://diposit.ub.edu/dspace/bitstream /2445/20946/7/Indaga_t_1.pdf

Hernández, F. (2008). La investigación basada en las artes. Propuestas para repensar la investigación en educación. Educatio Siglo XXI, 26, 85-118.

Huerta, R. (2014). La educación artística como motor de cambio social. Cuadernos de Pedagogía 449, 46-50.

Kester, G. (2011). The One and Other Many. Contemporary Collaborative Art in a Global Context. Durke University Press.

Luke, C. (1999). Feminismos y pedagogías en la vida cotidiana. Ediciones Morata.

Mesías-Lema, J. (2018). Artivismo y compromiso social: Transformar la formación del profesorado desde la sensibilidad. Comunicar 57, 19-28. https://doi.org/10.3916/C57-2018-02

Ministerio de Educación. (2018, 29 de mayo).Ley 21.091. Sobre Educación Superior. Biblioteca del Congreso Nacional. https://www.bcn.cl/leychile/navegar?idNorma=1118991

Miranda, F. (2014). De lo expositivo a la acción pedagógica. En S. Alonso y M. Craciun (Eds.), El ojo colectivo. Formas de hacer colectivo (pp. 163-168). Goethe-Institut.

Moreno, A. (2013). La cultura como agente de cambio social en el desarrollo comunitario. Arte, Individuo y Sociedad 25(1), 95-110.

Moreno, A. (2016). La mediación artística. Artes para la transformación social, la inclusión social y el desarrollo comunitario. Octaedro.

Mörsch, C. (2015). Una encrucijada de cuatro discursos. En A. Ceballos y A. Macaroff(Eds.), Contradecirse una misma. Museos y mediación educativa critica. Experiencias y reflexiones desde las educadoras de la documenta 12 (pp. 10-21). Fundación Museos de la Ciudad.

Rodrigo, J. (2010). Las pedagogías colectivas como trabajo en red: itinerarios posibles. En A. Collados y J. Rodrigo (Coords.), Transductores 3. Pedagogias colectivas y politicas espaciales (pp. 66-87). Centro José Guerrero.

Rodrigo, J. y Collados, A. (2014). Retos y complejidades de las prácticas artísticas colaborativas y las pedagogías colectivas. Pulso, (38), 57-72.

Rogoff, I. (2011). El Giro. Arte Y Politicas De Identidad 4, 253-266.

Sales, A., Traver, J. y Moliner, O. (2019). Redefiniendo el territorio de la escuela: espacios educativos y curriculum escolar para la transformación social. Revista Fuentes 21(2), 177-188. http://dx.doi.org/10.12795/revistafuent es.2019.v21.i2.03

Smith, A. (2004). Policy and Arts Education. En E. Eisner y M. Day (Eds.), Handbook of Research and Policy in Art Education (pp. 87-92). Naea.

Sullivan, G. (2010). Art Practice as Research. Inquiry in Visual Arts. Sage.

Velasco, S. (2015). Diez enclaves para apuntar al mundo. En A. Collados y J. Rodrigo (Eds.), Traductores 3. Prácticas artísticas en contexto. Itinerarios, útiles y estrategias (pp. 129-146). Centro José Guerrero.

Zúñiga, D. (2019). Los sentidos pedagógicos en una práctica artística dirigida para jóvenes dentro de un espacio cultural en Chile [Tesis doctoral, Universidad de Barcelona]. R https://www.tesisenred.net/handle/10803/668227 
Revista Humanidades, 2021, vol. 11, núM. 2, Julio-Diciembre, ISSN: 2215-3934

\section{Notas}

1 Se agradece a la Agencia Nacional de Investigación en Chile.

2 Estallido Social es el nombre que se le da al conflicto social originado en Santiago de Chile, propagado en las principales regiones del país el 18 de octubre de 2019. El hecho marca su inicio cuando estudiantes secundarios se organizan en masa para realizar evasiones al Metro Santiago tras el aumento de la tarifa de transportes, lo que generó una reacción en cadena en distintas partes del país y levantó consignas sociales que apuntaban a causas estructurales de descontento general. 